\title{
The phenomenal determination of retroaction and proaction: I. Interference within pairs of a single list
}

\author{
LEONARD BROSGOLE, WILLIAM G. LEDERER, and KATHLEEN D. KOZLOWSKI \\ St. John's University, Jamaica, New York 11499
}

\begin{abstract}
Two groups learned a paired-associate list to partial criterion. The stimulus and response items were similar for Group 1 and neutral for Group 2. Both groups were tested for stimulus and response recall $10 \mathrm{~min}$ and $24 \mathrm{~h}$ after original learning. In Group 1, stimulus recall did not change with time, but response recall decreased. To the contrary, both stimulus and response recall dropped with time in Group 2. It was concluded that the response items retroactively interfered with stimulus recall under conditions of similarity. In turn, the stimulus items seemed to recover with time to proactively interfere with response recall. Thus, retroaction and proaction have been demonstrated in the learning of a single list.
\end{abstract}

Retroaction and proaction are typically produced when original learning $(\mathrm{OL})$ is followed by the interpolated learning (IL) of similar material. Under this condition, the short-term recall of OL is relatively poor compared to the recall of IL. With the passage of time, however, the recall of OL remains stable (or may even improve), while there is marked forgetting of the interpolated task. The initial inferiority of $\mathrm{OL}$ is referred to as retroaction and the long-term effect upon IL is called proaction.

It is commonly held that the similarity between tasks results in a failure of discrimination, or list differentiation. Thus, list confusion is generated at the time of interpolated learning. It is alleged that this confusion is alleviated by the extinction, unlearning, or suppression of the originally learned responses, thereby permitting interpolated learning to occur. It follows logically that the short-term recall of the originally learned responses should be relatively poor, because of their extinction. With the passage of time, however, these responses should spontaneously recover and compete with the recall of the interpolated responses, resulting in the dramatic forgetting of interpolated learning. Accordingly, unlearning and competition of response seem to be critically involved in producing retroaction and proaction and, in fact, have become incorporated into what is known as two-factor theory.

It must be noted that the temporal separation of original and interpolated learning is essential to the two-factor approach, for it is the nonreinforced practice of original learning during a subsequent period of interpolated activity that supposedly leads to extinction. In a theoretical note, Brosgole (1976a) argued that perhaps unlearning is not at all involved in retroaction and proaction. It is entirely possible that these phenomena result from the manner in which materials are organized in memory. Perhaps the temporal division of lists merely provides a means by which tasks can be grouped in terms of which came first and which followed. In other words, it was speculated that retroaction and proaction may be the result of a perceptual state of primacy-recency, with time used as a means for achieving such grouping.

Brosgole (1976b) contended that a condition of phenomenal primacy-recency can be established in a single task, such as in the learning of a list of paired associates, where the stimuli are clearly sensed as coming before and leading to the response items. He presented subjects with a list consisting of 12 pairs of CVC trigrams, which were learned to a partial criterion of eight correct using the method of cued or aided recall. In a completely between-subjects design, stimulus and response recall was assessed $10 \mathrm{~min}$ and $24 \mathrm{~h}$ after original learning. On the basis of phenomenal primacyrecency, Brosgole (1976b) predicted an initial inferiority of stimulus recall with an improvement over time, accompanied by a deterioration in response recall over time. The data supported this speculation, as stimulus recall improved significantly from 3.3 stimuli at $10 \mathrm{~min}$ to 4.9 after $24 \mathrm{~h}$. Response recall dropped significantly from 6.1 items at $10 \mathrm{~min}$ to 4.7 after $24 \mathrm{~h}$. In addition, while there was significantly superior response recall at $10 \mathrm{~min}$, there was no difference by $24 \mathrm{~h}$. On the basis of an apparent spontaneous recovery of the perceptually prior items, coupled with a deterioration of the phenomenally recent items, Brosgole (1976b) concluded that retroaction and proaction were operative, with no possibility for extinction to occur.

Although the above data are in accord with the interference literature, it could be argued that they reflect something other than retroaction and proaction. After all, retroaction and proaction are typically defined with specific reference to a control, and there was no control group run in the study cited above. Accordingly, the following study was aimed at replicating the previous design with the insertion of an appropriate control. 
It was reasoned that if the disclosed effects, indeed, were retroaction and proaction, they should vary as a function of the similarity between the stimulus and response items. Accordingly, two groups were run, both having to learn a list of paired associates to partial criterion. The pairs consisted of similar items in the experimental group and neutral items in the control group. On the basis of the logic underlying this research, we expected the type of recall (S and $R$ ) to interact with time in the experimental group, but not in the control.

\section{METHOD}

\section{Subjects}

Thirteen males and 19 females participated in this study. They ranged in age from 18 to 54 years; the mean age was 24.9 years. All were naive as to the purpose of the study.

\section{Apparatus and Materials}

Paired-associate lists were presented on a Lafayette memory drum (Model 303). Similar and neutral lists were constructed using CVC trigrams (of $0 \%$ Glaze value) and three-digit members. Each list consisted of 12 pairs. Numbers and syllables were paired in the neutral lists, with the numbers as stimuli for half of the subjects and the syllables as stimuli for the remaining half. Essentially, the pairing consisted of a coupling of two serial lists, with the different materials carefully equated in terms of the amount of intraserial interference generated by each. The similar lists were syllable pairs for half the subjects and number pairs for the other half.

\section{Groups}

The subjects were divided into two groups of equal size. Whereas Group 1 had to learn a list of similar materials, Group 2 was required to master a neutral list.

\section{Procedure}

The subjects were told that this was a two-part experiment attempting to measure the difficulty with which different types of materials are learned. The materials would vary in meaningfulness, with different sets of items presented over a 2-day period. This was a subterfuge used in an attempt to prevent rehearsal prior to a 24-h test of recall. Of course, the intent of the study was explained at the conclusion of the procedure.

Each group was required to learn a respective list of pairs to a partial criterion of 8 out of 12 correct. The method of cued or aided recall was used, with the pairs presented at a 2 -sec rate and no delay between pairs. The subjects were required to pronounce each pair aloud as it appeared in the drum. Testing commenced $10 \mathrm{sec}$ after completion of the list exposure. The stimuli were presented in a different order, at a 2-sec rate, with the subject required to verbalize the correct response. The next trial began $30 \mathrm{sec}$ after completion of the test and the trials continued until criterion was achieved. The pairs appeared in three different orders and the order was varied over trials.

Completion of the list was followed by a 10-min break, after which all subjects were handed a sheet of paper and required to write down everything that they could remember from the list. They were prompted to include individual items when an entire pair could not be remembered. They were told, as well, not to be concerned about stimulus-response reversals. There was no time limit placed upon this test of free recall. The test was repeated $24 \mathrm{~h}$ later, when the subject returned.

In summary, each group was tested for stimulus and response recall after $10 \mathrm{~min}$ and $24 \mathrm{~h}$. Thus, type of recall and time were within-subject variables and stimulus-response similarity was a between-subjects factor.

\section{RESULTS AND DISCUSSION}

Group 1 met criterion in a mean of 45.2 trials, compared to 60.6 for Group 2. This difference was not significant $(\mathrm{t}=1.28$, df $=30)$. However, it must be pointed out that there was a distinct difference between lists in Group 1, as it was far easier to learn the syllable pairs (mean $=21.6$ trials) than it was to learn the number pairs (mean $=68.8$ trials). This is important because of the effect that will be subsequently noted in the recall data for the similar group. There was no difference observed between lists in Group 2. The mean number of correct responses to criterion was 196.4 and 197.4 for Groups 1 and 2, respectively. This difference was not significant $(t=.042, \mathrm{df}=30)$. Thus, the groups may be considered to be matched on original learning and, thereby, compared on the recall data.

In Group 1, stimulus recall improved somewhat from a mean of 6.0 at $10 \mathrm{~min}$ to 6.31 after $24 \mathrm{~h}$, while response recall diminished from 6.31 to 5.31. Both stimulus and response recall deteriorated with time in Group 2, with the stimuli declining from a mean of 6.75 to 5.0 items and the responses falling from 8.38 to 6.25 items. These data were transformed $\sqrt{(\text { mean }+.5)}$ and then subjected to a three-way analysis of variance using a split-plot factorial design.

There was a significant three-way interaction $(F=6.54, \mathrm{df}=1 / 30, p<.05)$. Simple effects revealed that Group 1 did not differ significantly in stimulus and response recall at $10 \mathrm{~min}$. This was a rather surprising finding which seemed to be related to the type of material learned. That is to say, the difference between stimulus and response recall was obscured by the arduous task of learning number pairs. Apparently this task was so confusing that the stimuli and responses were differentiated quite well during original learning. Thus, stimuli' and response recall was fairly even at the 10-min test. In fact, only one out of eight subjects recalled more responses than stimuli. However, there was significantly greater stimulus recall at the 24-h test $(\mathrm{F}=5.42, \mathrm{df}=1 / 60, \mathrm{p}<.05)$. While there was no reliable change in the number of stimulus items remembered from $10 \mathrm{~min}$ to $24 \mathrm{~h}$, response recall dropped significantly $(F=8.64$, df $=1 / 60, p<.01)$.

Group 2 recalled significantly more responses than stimuli at $10 \min (\mathrm{F}=11.71, \mathrm{df}=1 / 60, \mathrm{p}<.01)$ as well as at $24 \mathrm{~h}(\mathrm{~F}=7.59, \mathrm{df}=1 / 60, \mathrm{p}<.01)$. In addition, there was a significant deterioration in both stimulus $(F=29.03, \mathrm{df}=1 / 60, \mathrm{p}<.01)$ and response recall $(F=39.06, d f=1 / 60, p<.01)$ with time.

While Groups 1 and 2 did not differ in the number of stimuli remembered at $10 \mathrm{~min}$, Group 2 did recall significantly more response items $(F=11.79$, $\mathrm{df}=1 / 120, \mathrm{p}<.01)$. Just the opposite obtained after $24 \mathrm{~h}$, as the two groups became equivalent in response recall, but Group 1 remembered significantly more stimuli $(F=6.7, \mathrm{df}=1 / 120, \mathrm{p}<.05)$. 
In summary, stimulus-response similarity effected an interaction of Type of Recall by Time. That is to say, while the recall of phenomenally different material diminished with time, the perceptually prior items remained constant. The fact that this interaction did not obtain with stimulus response neutrality supports the proposition that retroaction and proaction can occur within the learning of a single list of pairs. Such a speculation was further bolstered by the frequency data regarding changes in stimulus recall with time.

Of the 16 subjects in the similar group, only 8 showed a change in stimulus recall from $10 \mathrm{~min}$ to $24 \mathrm{~h}$. Of these, five increased and three decreased. This can be compared to the neutral group, where there was only one increase and 14 decreases. These two distributions were significantly different according to the Fisher test of exact probability $(\mathrm{p}<.01)$. Thus, it may be contended that there was evidence for the "spontaneous recovery" of the perceptually prior items under conditions of similarity.
In conclusion, the response items in a paired-associate list retroactively interfere with stimulus recall under conditions of similarity. There is an apparent recovery of these items with the passage of time, and they come to proactively interfere with response recall. It would seem that retroaction and proaction are produced by a sense of phenomenal "primacy-recency" under conditions of similarity. There does not seem to be a need for unlearning generated by an interpolated period of nonreinforced practice. Thus, the "two-factor" theory may be seriously questioned.

\section{REFERENCES}

Brosgole, L. Phenomenal determination of retroactive and proactive interference. Psychological Reports, 1976, in press. (a) Brosgole, L. Associative symmetry: V. An interference interpretation of the failure of stimulus availability. Bulletin of the Psychonomic Society, 1976, 7, 177-178. (b)

(Received for publication May 20, 1976.) 